\title{
Occipitocervical fusion of traumatic atlanto-occipital dissociation in a patient with autofused cervical facet joints: illustrative case
}

\author{
J. Manuel Sarmiento, MD, Daniel Chang, MD, Peyton L. Nisson, MD, Julie L. Chan, MD, PhD, and Tiffany G. Perry, MD \\ Department of Neurosurgery, Cedars-Sinai Medical Center, Los Angeles, California
}

BACKGROUND Patients who survive traumatic atlanto-occipital dissociation (AOD) may present with normal neurological examinations and nearnormal-appearing diagnostic images, such as cervical radiographs and computed tomography (CT) scans.

OBSERVATIONS The authors described a neurologically intact 64-year-old female patient with a degenerative autofusion of her right C4-5 facet joints who presented to their center after a motor vehicle collision. Prevertebral soft tissue swelling and craniocervical subarachnoid hemorrhage prompted awareness and consideration for traumatic AOD. An abnormal occipital condyle-C1 interval $(4.67 \mathrm{~mm})$ on CT and craniocervical junction ligamentous injury on magnetic resonance imaging (MRI) confirmed the diagnosis of AOD. Her autofused right C4-5 facet joints were incorporated into the occipitocervical fusion construct.

LESSONS Traumatic AOD can be easily overlooked in patients with a normal neurological examination and no associated upper cervical spine fractures. A high index of suspicion is needed when evaluating CT scans because normal values for craniocervical parameters are significantly different from the accepted ranges of normal on radiographs in the adult population. MRI of the cervical spine is helpful to evaluate for atlanto-occipital ligamentous injury and confirm the diagnosis. Occipitocervical fusion construct may need to be extended to incorporate spinal levels with degenerative autofusion to prevent adjacent level degeneration.

https://thejns.org/doi/abs/10.3171/CASE21276

KEYWORDS atlanto-occipital dissociation; atlanto-occipital dislocation; degenerative facet fusion; facet joint autofusion; occipitocervical fusion

Atlanto-occipital dissociation (AOD) is an uncommon injury, with an incidence of $0.2 \%$ to $0.6 \%$, whereby the skull is forcibly separated from the upper cervical spine due to a tremendous amount of traumatic blunt force. ${ }^{1,2} \mathrm{AOD}$ is historically considered a fatal diagnosis, but the advent of improved prehospital systems and shorter transportation times have increased the number of survivors of this devastating injury. ${ }^{3}$ Early treatment with occipitocervical fixation or halo vest immobilization is paramount because of the severe spinal instability that is associated with AOD. Nearly all patients who are not treated develop some form of neurological decline, and many never fully recover neurological function. ${ }^{4}$

Proper initial diagnosis of $A O D$ can be challenging for several reasons. First, $A O D$ is foremost a ligamentous injury that is not always associated with coexisting upper cervical spine fractures.
Second, cervical radiographs may be inadequate or difficult to interpret, and even established radiographic indices on computed tomography (CT) may be normal depending on the severity and type of AOD. Third, patients with AOD may be neurologically intact, which further decreases the suspicion of upper cervical spine injuries. Finally, the upper cervical spine has a complex anatomical configuration; therefore, the radiographic criteria for instability in this region of the spine in patients with a normal-appearing radiograph or CT scan remain controversial. ${ }^{5}$ The following illustrative case highlights a neurologically intact patient who presented with AOD after a motor vehicle collision and was found to have autofused facet joints on CT. The rationale for diagnostic work-up and the proposed surgical plan in light of this patient's cervical facet autofusion are discussed.

ABBREVIATIONS AOD = atlanto-occipital dissociation; $\mathrm{BAI}=$ basion-axial interval; $\mathrm{BDI}=$ basion-dens interval; $\mathrm{CCl}=$ condyle-C1 interval; $\mathrm{CT}=$ computed tomography; $\mathrm{MRI}=$ magnetic resonance imaging; $\mathrm{PAL}=$ posterior axial line; $\mathrm{STIR}=$ short tau inversion recovery.

INCLUDE WHEN CITING Published July 5, 2021; DOI: 10.3171/CASE21276.

SUBMITTED May 4, 2021. ACCEPTED May 24, 2021.

(C) 2021 The authors, CC BY-NC-ND 4.0 (http://creativecommons.org/licenses/by-nc-nd/4.0/). 


\section{Illustrative Case}

The patient was a 64-year-old woman without any significant medical history who presented to the emergency department after a motor vehicle collision. She was a restrained driver in a vehicle that was struck on the driver's side by a truck traveling approximately 40 to 45 miles per hour at an intersection. Her airbags were deployed, and she had to be extricated from the vehicle. On evaluation she was awake, alert, and following commands. She endorsed intractable nausea and sharp, diffuse neck pain. She did not exhibit any cranial nerve palsies. On strength examination, she exhibited pain-limited $4+$ movements in her bilateral upper extremities and full strength in her bilateral lower extremities. Sensation was intact to light touch in all four extremities. Other than $3+$ reflexes in her patellar reflexes, she did not have other signs of hyperreflexia on the rest of her deep tendon reflexes. Hoffman's sign, Babinski's reflex, and clonus were not present.

CT of the brain demonstrated a scant amount of subarachnoid hemorrhage in the left posterior Sylvian fissure as well as subarachnoid blood anterior to the medulla at the level of the foramen magnum (Fig. 1). CT of the cervical spine demonstrated splaying of the right occiput to the $\mathrm{C} 1$ condylar space and diastasis of the right $\mathrm{C} 1-2$ facet as well as significant prevertebral edema along the entire cervical spine (Fig. 2). Of note, the patient had a degenerative autofusion of the right $\mathrm{C} 4-5$ facet joints. The basion-dens interval (BDI) was $10.1 \mathrm{~mm}$, basion-posterior axial line (PAL) distance was $11.9 \mathrm{~mm}$, Powers ratio was 1.13 , and right condyle-C1 interval (CCl) was 4.67 $\mathrm{mm}$ (Fig. 3). CT angiography of the neck was negative for internal carotid artery or vertebral artery dissection. Magnetic resonance imaging (MRI) of the cervical spine demonstrated T2-weighted imaging and short tau inversion recovery (STIR) signal hyperintensity at the craniocervical junction, suggesting ligamentous injury. Specifically, injury to the atlanto-occipital ligament, apical ligament, tectorial membrane, transverse ligament, and posterior ligamentous complex was observed. There was also significant prevertebral edema spanning from the basion to $\mathrm{C} 5$ as well as evidence of hemorrhage in the cervicomedullary junction (Fig. 4). Together, these imaging findings were concerning for a Type 2 AOD.

Surgery was recommended for stabilization of the occipitocervical junction, to which the patient and her spouse consented. The plan was made for occiput to C5 posterior instrumentation and arthrodesis with tricortical ileum structural allograft. The patient was
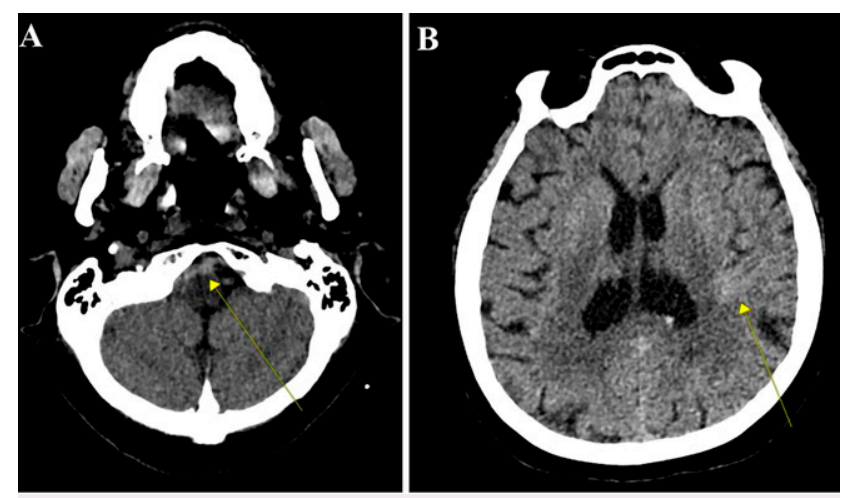

FIG. 1. Initial CT of the head demonstrating subarachnoid hemorrhage ventral to the medulla (arrow; $\mathbf{A})$ and within the left posterior Sylvian fissure (arrow; B).
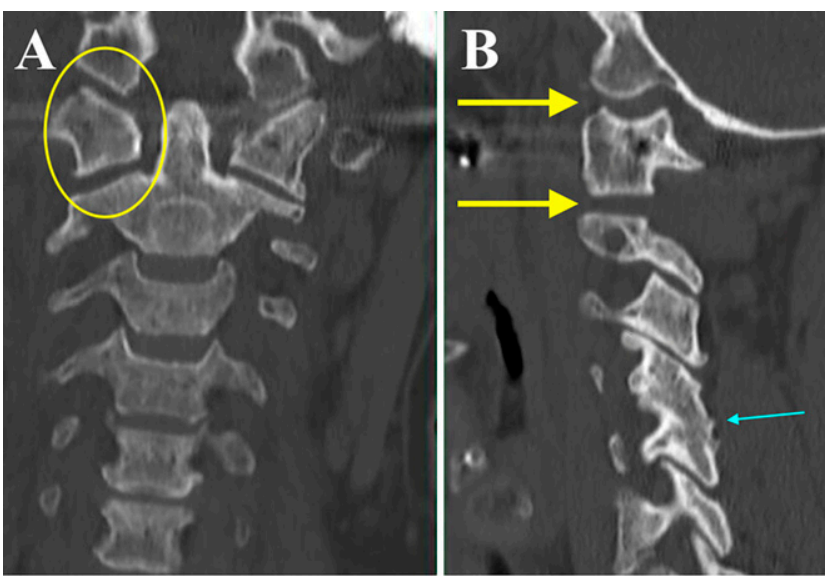

FIG. 2. A: Coronal CT of the cervical spine demonstrating splaying of right occiput-C1 and C1-2 space relative to left side (circle). B: Sagittal CT demonstrating splayed segments on right side with some air in occiput-C1 space (yellow arrows) as well as fused right C4-5 facet (blue arrow).

secured in Mayfield pins and carefully placed prone, with confirmation of neutral head positioning with relation to her shoulders and the rest of her body through both visual inspection and occipitocervical alignment on fluoroscopy. Motor evoked potentials and somatosensory evoked potentials were monitored and remained stable throughout the procedure. A midline incision and exposure were performed from occiput to $\mathrm{C} 5$, with the posterior arch of $\mathrm{C} 1$ exposed. A reference frame was sterilely attached to the Mayfield pins and an intraoperative O-ARM stereotactic navigation (Medtronic) spin was obtained, followed by registration of instruments and verification of navigational accuracy. Pilot holes were first made for bilateral $\mathrm{C} 2$ pedicle screws and bilateral lateral mass screws at $\mathrm{C} 3, \mathrm{C} 4$, and $\mathrm{C} 5$. Two 20-mm pedicle screws were placed in $\mathrm{C} 2$ while 14-mm lateral mass screws were placed in $\mathrm{C} 3, \mathrm{C} 4$, and C5. To achieve a smoother and less acute rod angle, no instrumentation was placed at $\mathrm{C} 1$. A small occipital plate was fixed to the occipital bone using three 12-mm screws along the midline keel and two 6-mm screws laterally. The occipital bone, posterior arch of $\mathrm{C} 1$ and lateral masses, and facet joints of $\mathrm{C} 2$ to $\mathrm{C} 5$ were decorticated. A tricortical ilium graft was wedged from the occipital bone over the $\mathrm{C} 1$ bone to the top of the decorticated $\mathrm{C} 2$ and fashioned with troughs bilaterally in preparation for prebent rods. Postoperative radiographs showed good alignment of the occiput to the cervical spine (Fig. 5). The patient recovered well from the surgery, her nausea resolved after the procedure, and she was discharged to a rehabilitation center after an uneventful postoperative course and stable neurological examination.

\section{Discussion}

\section{Observations}

Summary of Case

This illustrative case focuses on a 64-year-old woman who had a traumatic Type 2 distraction-type AOD after a motor vehicle collision. She presented with a near normal neurological examination and autofused facet joints. AOD can be frequently missed even by experienced clinicians because it is primarily an injury to the ligaments between the occiput and upper cervical spine. Furthermore, there is not always an associated upper cervical fracture that draws 

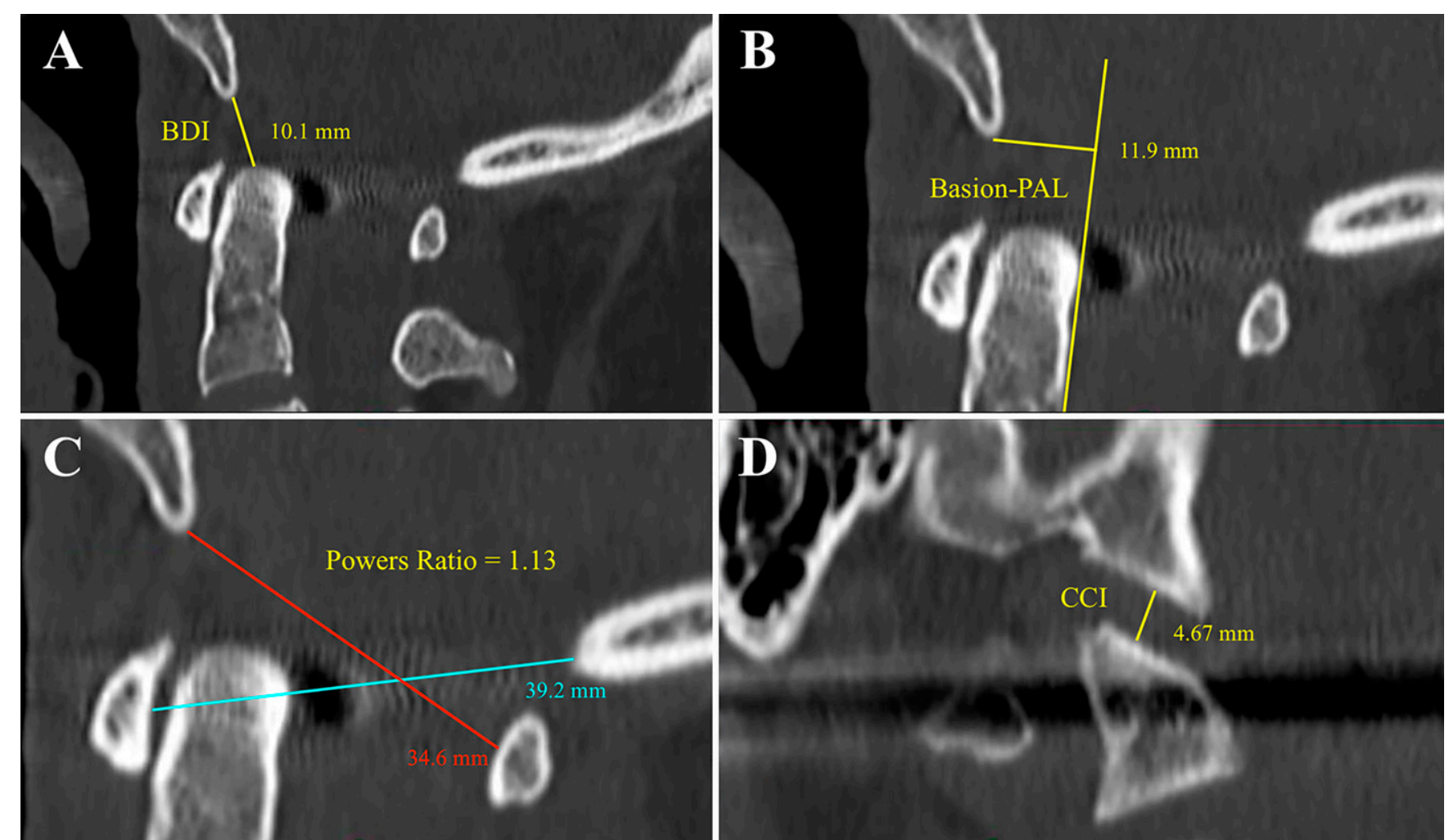

FIG. 3. A: Calculation of $\mathrm{BDI}$ is $10.1 \mathrm{~mm}$. B: Calculation of basion-PAL is $11.9 \mathrm{~mm}$. C: Powers ratio, which equals the ratio between the distance of the basion to the posterior arch of $\mathrm{C} 1$ (red line) over that of the opisthion to the anterior arch of C1 (blue line), is 1.13. D: Calculation of the occipital CCl is $4.67 \mathrm{~mm}$.

attention to the craniocervical junction. Thus, correctly diagnosing this uncommon injury requires a high index of suspicion and a thorough investigation of the craniocervical junction. At first glance, the upper cervical spine may sometimes appear normal on CT in some patients. The craniocervical parameters in our patient were abnormal based on CT criteria of the BDI, Powers ratio, and $\mathrm{CCl}$. Her prevertebral soft tissue swelling and craniocervical subarachnoid hemorrhage also prompted awareness and consideration for AOD. The abnormal craniocervical junction ligamentous injury on MRI further confirmed the diagnosis of AOD. She was kept immobilized in a hard cervical collar with cervical c-spine precautions until surgery for internal fixation and fusion.

\section{Rationale for Surgical Plan}

The patient's existing right congenital $\mathrm{C} 4-5$ facet fusion had to be taken into consideration when planning our surgical approach. We believed it was important to include the C4 and C5 levels in the posterior fusion construct to reduce the risk of accelerated
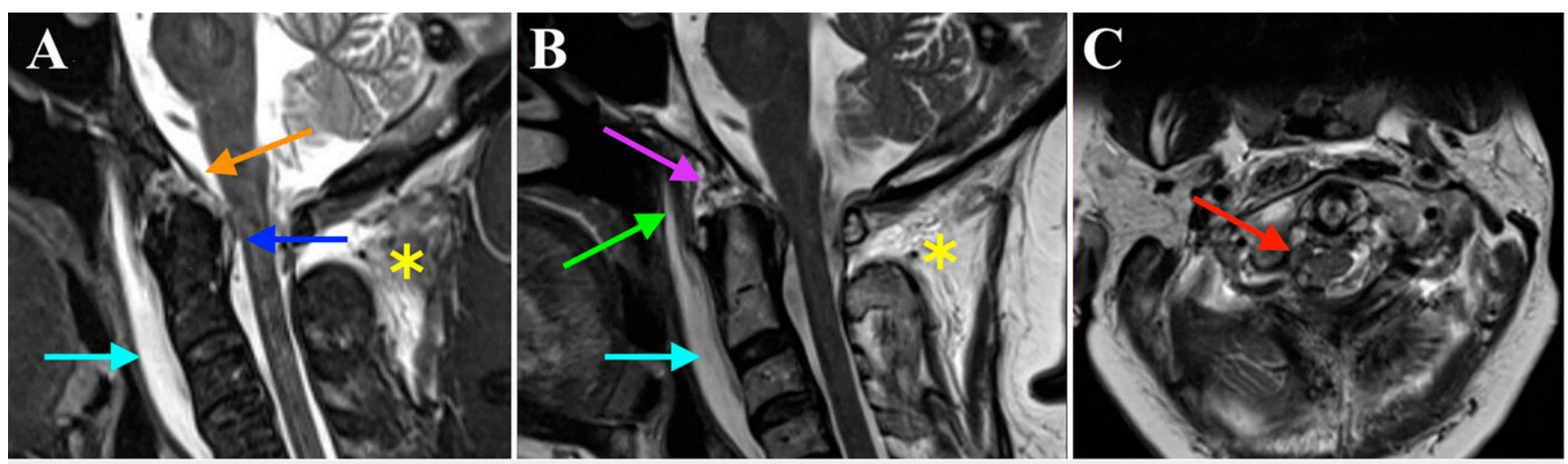

FIG. 4. Sagittal MRI of the cervical spine without gadolinium showing STIR (A) and T2-weighted imaging (B) signal hyperintensity at the craniocervical junction, suggesting ligamentous injury. Specifically, injury to the atlanto-occipital ligament (B, green arrow), apical ligament (B, purple arrow), tectorial membrane ( $\mathbf{A}$, orange arrow), transverse ligament ( $\mathbf{A}$, dark blue arrow), and posterior ligamentous complex ( $\mathbf{A}$ and $\mathbf{B}$, yellow asterisks) was observed. Prevertebral edema from basion to $\mathrm{C} 5$ is also apparent (A and B, light blue arrows). Axial MRI (C) of the cervical spine without gadolinium demonstrating epidural blood (red arrow) seen in the cervicomedullary junction toward the right side. 

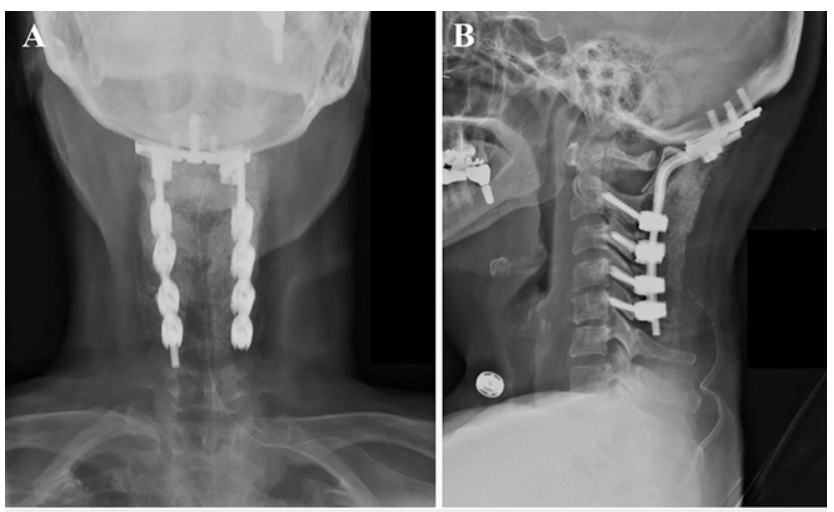

FIG. 5. Postoperative upright radiographs showing good alignment of occiput to cervical spine in the anteroposterior $(\mathbf{A})$ and lateral (B) views.

degeneration of the C3-4 level. It is apparent that hypermobility at the adjacent levels of a fusion construct may generate degenerative changes in nonfused segments. ${ }^{6}$ Therefore, performing an occiput-C2 or occiput-C3 fusion in this patient would expose the C3-4 level to further accelerated changes and hypermobility due to the autofusion of the caudal C4-5 level. Biomechanical studies have shown that intradiscal pressure at intervertebral levels adjacent to cervical fusions increases by approximately $50 \%$ in the proximal adjacent level and $125 \%$ in the distal adjacent level. ${ }^{7}$ Furthermore, the additional segmental fixation at C4 and C5 acts to decrease the lever arm of the bone-screw cantilever model. This ultimately reduces hardware failure because the screw-bone interface experiences a moment force proportional to the length of the lever arm, as determined by the length of rod between fixation points. ${ }^{8}$ Adding intervening lateral mass screws at the C3, C4, and C5 levels serves to decrease the length of this lever arm and reduce of magnitude of the applied moment force.

\section{Diagnosis of AOD}

An accurate and timely diagnosis as well as proper treatment of AOD are of utmost importance. Historically, AOD was classified into three types based on the direction of dislocation as described by Traynelis et al.: anterior (Type I), longitudinal (Type II), and posterior (Type III) dislocation of the occiput from the cervical spine. ${ }^{9}$ Despite the classifications, there is a lack of consensus regarding the best measurement technique in the diagnosis of AOD. Original descriptions of the diagnosis of $A O D$ were based on radiographs and include $\mathrm{BDI}>10 \mathrm{~mm}$ by Wholey et al. $^{10}$ and the Powers ratio measuring the basion to posterior atlas distance divided by the distance between the opisthion and anterior atlas (Powers ratio $>1){ }^{11}$ These two methods are the most commonly encountered; however, alternative measurements describe distances between the mandible and the atlas or axis, as described by Dublin et al. ${ }^{12}$ The sensitivity of the various radiographic diagnostic techniques have been considered a point of debate. A study by Lee et al. determined that the sensitivity of the Wholey method, Powers ratio, and Dublin's method was $50 \%, 33 \%$, and $25 \%$, respectively, ${ }^{13}$ whereas Harris et al. determined that the basion-axial interval (BAI)-BDI method was $100 \%$ sensitive on lateral cervical spine radiographs. ${ }^{14}$ Specifically, Harris et al. described that improved detection of AOD is achieved by measuring both $\mathrm{BAI}$ and $\mathrm{BDI}$, where $\mathrm{BAl}$ is the distance from the basion to the $\mathrm{C} 2$ posterior line and $\mathrm{BDI}$ is the distance from the basion to the tip of the dens (abnormal BAl and BDI >12 mm). ${ }^{14,15}$ The improved sensitivity likely stems from the combination of these two measurements, in which BDI more consistently captures Type II dislocations and BAI identifies Types I and III dislocations. Trauma guidelines by Theodore et al. describe level III evidence that lateral cervical radiographs are the preferred imaging modality to obtain $\mathrm{BAI}-\mathrm{BDI}$, and when taken together, the Harris method is the most reliable radiographic analysis in the diagnosis of $A O D .^{4}$ If radiographs are inadequate, then additional imaging with CT and MRI is needed to confirm the diagnosis of AOD. It is important to keep in mind that normal values for craniocervical parameters are significantly different from the accepted ranges of normal on radiographs in the adult population. For instance, the normal values of BDI and Powers ratio on CT scan are $<8.5$ and 0.9 , respectively. ${ }^{16}$ The $\mathrm{BAI}$ is highly variable in adults and is associated with a high standard error, making it difficult to ascribe a normal value based on CT. A CT-based occipital $\mathrm{CCl}$ of $1.5 \mathrm{~mm}$ (condylar sum of $3.0 \mathrm{~mm}$ ) cutoff value had the highest sensitivity and specificity for the diagnosis of $A O D$ in the adult population, according to Martinez-Del-Campo et al. ${ }^{17}$

\section{MRI for AOD}

The principal structures that confer stability to the atlanto-occipital joint are the alar ligaments, tectorial membrane, and atlanto-occipital joint capsules. ${ }^{18}$ Deciding on stability of the upper cervical spine remains a challenge. There are several different classification systems, yet none of them consider combination injuries of the upper cervical spine. ${ }^{5}$ The Harborview group proposed a new classification for $A O D$ involving the combination of static and dynamic imaging plus MRI. ${ }^{19}$ However, many clinicians may be deterred from this classification given the need to perform dynamic testing to detect instability of an injured upper cervical spine. Horn et al. proposed a simple grading system for atlanto-occipital injuries to determine stability of the upper cervical spine that incorporated abnormal findings on CT and ligamentous injury on MRI. ${ }^{20}$ Based on this classification system, Grade I injuries are designated by normal CT findings in relation to established methods of diagnosis (the Powers ratio, BDI, BAI-BDI, and $\mathrm{X}$-line) but have moderately abnormal MRI findings (high posterior ligaments or atlanto-occipital signal). The authors support nonoperative treatment in patients with Grade I injuries. Grade II injuries include a minimum of one abnormal finding on CT based on established diagnostic criteria or grossly abnormal MRI findings in the atlanto-occipital joints, tectorial membrane, alar ligaments, or cruciate ligaments. In these patients, surgical fixation is recommended. Using the Horn et al. classification, our patient was deemed to have a Grade II injury and therefore considered to have upper cervical spine instability based on CT and MRI criteria.

\section{Treatment of AOD}

Among the available treatment modalities, external immobilization using a halo orthosis and craniocervical fusion are the mainstays of treatment. Traction is not a recommended treatment option for patients with $A O D$ because there is a high risk $(10 \%)$ of neurological deterioration. ${ }^{4}$ Based on the 2013 Congress of Neurological Surgeons guidelines and systematic review by Theodore et al., treatment with internal fixation and fusion remains a level 3 evidence-based recommendation. ${ }^{4}$ Importantly, of the 12 patients who were treated with external orthosis, $4(33 \%)$ worsened transiently and required subsequent craniocervical fusion. Of the remaining 8 patients managed 
with external immobilization alone, $3(37.5 \%)$ remained unstable after 6 to 22 weeks of immobilization. Comparatively, only 1 of 29 patients $(3.4 \%)$ with planned early craniocervical fusion worsened neurologically after surgery. In this group, no patients experienced late instability that required another operation. Failure to treat $A O D$ resulted in neurological worsening in 7 of 13 patients $(54 \%)$. Therefore, early diagnosis and treatment with craniocervical fusion are recommended in patients with AOD. Treatment with external immobilization alone is associated with unacceptably high rates of neurological deterioration and nonunion.

\section{Prognosis of Patients with AOD}

Autopsy studies report an AOD rate of incidence up to $8 \%$ among patients who die on scene after a high-energy mechanism of injury. ${ }^{21}$ Because the annual incidence of patients with $A O D$ who present to the emergency department ranges only from $0.2 \%$ to $0.6 \%$, it is readily apparent that $A O D$ is associated with a high mortality rate. ${ }^{1,2} \mathrm{AOD}$ is often commonly associated with traumatic brain injury. Patients who survive AOD may present with neurological deficits such as lower cranial nerve palsies, unilateral or bilateral weakness, or quadriplegia. However, nearly $20 \%$ of patients with traumatic AOD have a normal neurological examination, which may delay or cause clinicians to miss the diagnosis, particularly in patients who also have normalappearing initial cervical radiographs. ${ }^{4}$ To emphasize the difficulty of making the diagnosis, consider a report by Souslian et al. that described a 37-year-old polytrauma patient who had traumatic AOD after a high-speed motor vehicle accident. ${ }^{22}$ The patient had normal occiput-C1 craniometric parameters and unexplained perimesencephalic subarachnoid hemorrhage. Cervical MRI showed evidence of disruption of more than two atlanto-occipital ligaments, which led to the diagnosis and subsequent halo immobilization followed by occipitocervical fusion. ${ }^{22}$ Schellenberg et al. queried the National Trauma Data Bank in 2018 and showed that traumatic AOD is not as devastating as previously considered because $78 \%$ of patients who arrived alive to the hospital survived to discharge. ${ }^{23}$ In that database study, 1,489 patients were diagnosed with AOD almost exclusively after blunt traumatic mechanisms (97\%), particularly after motor vehicle collisions (66\% of cases). Lower age, lower Injury Severity Score, and higher Glasgow Coma Scale score on admission independently predicted survival, but time to neurosurgical intervention did not. A 15-year retrospective study by Mendenhall et al. at Vanderbilt University reported 22 patients with early diagnosis of AOD followed by surgery with occipitocervical fusion and 9 patients with a failed diagnosis of $\mathrm{AOD}^{2}$ Missed AOD was the strongest predictor of mortality, and patients with better American Spinal Cord Injury Association scores were associated with missed $A O D$ cases.

\section{Lessons}

Traumatic AOD can be easily overlooked in patients with a normal neurological examination and no associated upper cervical spine fractures. A high index of suspicion is needed when evaluating CT scans because normal values for craniocervical parameters are significantly different from the accepted ranges of normal on radiographs in the adult population. MRI of the cervical spine is helpful in evaluating for atlanto-occipital ligamentous injury and confirming the diagnosis. Occipitocervical fusion may need to be extended to incorporate spinal levels with degenerative autofusion to prevent adjacent level degeneration.

\section{References}

1. Mueller FJ, Kinner B, Rosskopf M, et al. Incidence and outcome of atlanto-occipital dissociation at a level 1 trauma centre: a prospective study of five cases within 5 years. Eur Spine J. 2013;22(1): $65-71$.

2. Mendenhall SK, Sivaganesan A, Mistry A, et al. Traumatic atlantooccipital dislocation: comprehensive assessment of mortality, neurologic improvement, and patient-reported outcomes at a Level 1 trauma center over 15 years. Spine J. 2015;15(11):2385-2395.

3. Labler L, Eid K, Platz A, et al. Atlanto-occipital dislocation: four case reports of survival in adults and review of the literature. Eur Spine J. 2004;13(2):172-180.

4. Theodore N, Aarabi B, Dhall SS, et al. The diagnosis and management of traumatic atlanto-occipital dislocation injuries. Neurosurgery. 2013;72(suppl 2):114-126.

5. Liao S, Jung MK, Hörnig L, et al. Injuries of the upper cervical spine: how can instability be identified? Int Orthop. 2020;44(7): 1239-1253.

6. Laratta JL, Shillingford JN, Saifi C, Riew KD. Cervical disc arthroplasty: a comprehensive review of single-level, multilevel, and hybrid procedures. Global Spine J. 2018;8(1):78-83.

7. Dmitriev AE, Cunningham BW, Hu N, et al. Adjacent level intradiscal pressure and segmental kinematics following a cervical total disc arthroplasty: an in vitro human cadaveric model. Spine (Phila Pa 1976). 2005;30(10):1165-1172.

8. Wolfia C, Eckardt G, Yoganandan N. Implant attributes: cantilever beam fixation. In: Steinmetz MP, Benzel EC, eds. Benzel's Spine Surgery: Techniques, Complication Avoidance, and Management. 4th ed. Elsevier Churchill Livingstone; 2016:349-355.

9. Traynelis VC, Marano GD, Dunker RO, Kaufman HH. Traumatic atlanto-occipital dislocation. Case report. J Neurosurg. 1986;65(6): 863-870.

10. Wholey MH, Bruwer AJ, Baker $\mathrm{HL} J$ r. The lateral roentgenogram of the neck; with comments on the atlanto-odontoid-basion relationship. Radiology. 1958;71(3):350-356.

11. Powers B, Miller MD, Kramer RS, et al. Traumatic anterior atlantooccipital dislocation. Neurosurgery. 1979;4(1):12-17.

12. Dublin $A B$, Marks WM, Weinstock $D$, Newton TH. Traumatic dislocation of the atlanto-occipital articulation (AOA) with short-term survival. With a radiographic method of measuring the AOA. $J$ Neurosurg. 1980;52(4):541-546.

13. Lee $\mathrm{C}$, Woodring $\mathrm{JH}$, Goldstein SJ, et al. Evaluation of traumatic atlantooccipital dislocations. AJNR Am J Neuroradiol. 1987;8(1): 19-26.

14. Harris JH Jr, Carson GC, Wagner LK, Kerr N. Radiologic diagnosis of traumatic occipitovertebral dissociation: 2. comparison of three methods of detecting occipitovertebral relationships on lateral radiographs of supine subjects. AJR Am J Roentgenol. 1994;162(4): 887-892.

15. Harris JH Jr, Carson GC, Wagner LK. Radiologic diagnosis of traumatic occipitovertebral dissociation: 1. normal occipitovertebral relationships on lateral radiographs of supine subjects. AJR Am J Roentgenol. 1994;162(4):881-886.

16. Rojas CA, Bertozzi JC, Martinez CR, Whitlow J. Reassessment of the craniocervical junction: normal values on CT. AJNR Am J Neuroradiol. 2007;28(9):1819-1823.

17. Martinez-Del-Campo E, Kalb S, Soriano-Baron H, et al. Computed tomography parameters for atlantooccipital dislocation in adult patients: the occipital condyle-C1 interval. J Neurosurg Spine. 2016;24(4):535-545. 
18. Maserati MB, Stephens B, Zohny Z, et al. Occipital condyle fractures: clinical decision rule and surgical management. J Neurosurg Spine. 2009;11(4):388-395.

19. Bellabarba C, Mirza SK, West GA, et al. Diagnosis and treatment of craniocervical dislocation in a series of 17 consecutive survivors during an 8-year period. J Neurosurg Spine. 2006;4(6):429-440.

20. Horn EM, Feiz-Erfan I, Lekovic GP, et al. Survivors of occipitoatlantal dislocation injuries: imaging and clinical correlates. J Neurosurg Spine. 2007;6(2):113-120.

21. Garrett M, Consiglieri G, Kakarla UK, et al. Occipitoatlantal dislocation. Neurosurgery. 2010;66(suppl 3):48-55.

22. Souslian FG, Patel PD, Elsherif MA. Atlanto-occipital dissociation in the setting of relatively normal radiologic findings. World Neurosurg. 2020;143:405-411.

23. Schellenberg $M$, Inaba $K$, Cheng $V$, et al. Independent predictors of survival after traumatic atlanto-occipital dissociation. J Trauma Acute Care Surg. 2018;85(2):375-379.

\section{Disclosures}

The authors report no conflict of interest concerning the materials or methods used in this study or the findings specified in this paper.

\section{Author Contributions}

Conception and design: Perry, Sarmiento, Chang, Nisson. Acquisition of data: Perry, Sarmiento, Chang, Nisson. Analysis and interpretation of data: Perry, Sarmiento, Chang, Chan. Drafting the article: Sarmiento, Chang, Nisson, Chan. Critically revising the article: Perry, Sarmiento, Chang, Chan. Reviewed submitted version of manuscript: all authors Approved the final version of the manuscript on behalf of all authors: Perry. Administrative/technical/material support: Sarmiento.

\section{Correspondence}

Tiffany G. Perry: Cedars-Sinai Medical Center, Los Angeles, CA. tiffany.perry@csmns.org. 